\title{
Creep and stress relaxation of a FeMnSi-based shape memory alloy at low temperatures
}

\author{
C. Leinenbach ${ }^{1, *}$, W.J. Lee ${ }^{1,2}$, A. Lis ${ }^{1}$, A. Arabi-Hashemi ${ }^{1}$, C. Cayron ${ }^{3}$, B. Weber ${ }^{1}$
}

${ }^{1}$ Empa, Swiss Federal Laboratories for Materials Science and Technology

Überlandstrasse 129, CH-8600 Dübendorf, Switzerland

\footnotetext{
${ }^{2}$ Korea Institute of Industrial Technology, Jisa-dong, Gangseo-gu, Busan 618-230, Republic of Korea

${ }^{3}$ Laboratory of Thermo Mechanical Metallurgy (LMTM), PX Group Chair, Ecole Polytechnique

Fédérale de Lausanne (EPFL), Rue de la Maladière 71b, 2000 Neuchâtel, Switzerland
}

\begin{abstract}
*Corresponding author
Dr. Christian Leinenbach

Empa-Swiss Federal Laboratories for Materials Science and Technology

Überlandstrasse 129
\end{abstract}

CH-8600 Dübendorf

Tel.: +41587654518

e-mail: christian.leinenbach@empa.ch 


\begin{abstract}
The creep and stress relaxation behavior of a $\mathrm{Fe}-17 \mathrm{Mn}-5 \mathrm{Si}-10 \mathrm{Cr}-4 \mathrm{Ni}-1(\mathrm{~V}, \mathrm{C})(\mathrm{wt}-\%)$ shape memory alloy at low homologous temperatures $\left(-45^{\circ} \mathrm{C}<\mathrm{T}<50^{\circ} \mathrm{C}\right)$ was systematically studied in stress and strain controlled tensile tests. At constant stresses at $-45^{\circ} \mathrm{C}$, the alloy exhibits pronounced creep up to $0.6 \%$ at $600 \mathrm{MPa}$ after only 30 minutes holding time. If the strain is kept constant, a pronounced stress relaxation of up to $10 \%$ of the initial stress was observed. The final creep strains, the creep rates at a constant stress as well as the stress relaxation at a constant strain increase with decreasing temperature. In addition, the change of the recovery stress as a function of time in a restrained sample after $4 \%$ elongation and heating to different constant temperatures was monitored. It was observed that the increase of the final recovery stress is more pronounced when the holding temperature is increased. This behavior was explained with the time and temperature dependent formation of stress induced $\varepsilon$ martensite from the parent $\gamma$-austenite phase during mechanical loading according to the model of Kajiwara et al. as well as with the increased number of stacking faults at lower temperatures, which serve as nucleation sites for the $\varepsilon$-martensite formation.
\end{abstract}

Keywords: Fe-based shape memory alloy; low temperature creep; stress relaxation; martensitic transformation 


\section{Introduction}

Fe-based shape memory alloys (SMAs) have attracted much attention regarding their use for civil engineering applications due to their low cost, good mechanical properties and excellent workability. As has been discovered by Sato et al. in 1982 [1], the shape memory effect (SME) in FeMnSi-based SMAs originates from the stress-induced phase transformation of the fcc $\gamma$-austenite phase into hcp $\varepsilon$ martensite and its reverse transformation upon heating. Since then, extensive studies have been carried out on transformation behavior [2], physical properties [2,3] and improving the SME [4]. More recently, it has been shown that the SME can be improved significantly by introducing fine precipitates, such as $\mathrm{NbC}$ or $\mathrm{VC}$, into the austenite matrix [5-10]. These precipitates do not only improve the SME by providing potential nucleation sites for the martensite phase, but also can increase the strength of the austenite phase [6].

Possible applications of SMAs are passive vibration damping and energy dissipation, active vibration control, actuator applications and the utilization of the SME for prestressing of concrete structures [1114]. For the latter application, SMA bars or wires are elongated and cast in the concrete. The constrained SMA is then heated above the transformation temperature. Since the SMA cannot recover its strain, tensile stresses in the bars or wires and compressive stresses in the concrete will build up [15].

With regard to civil engineering applications, some of the present authors have recently developed a Fe-17Mn-6Si-10Cr-4Ni-1(V,C) SMA which showed very promising properties [9, 10, 14-19]. This alloy can generate a high recovery stress of up to $500 \mathrm{MPa}$ after heating to a temperature of only 130 $160^{\circ} \mathrm{C}$, a comparably high fatigue strength, and the alloy can be produced by a relatively cheap manufacturing process with casting in atmospheric conditions.

In a previous work, we have observed a small but significant increase of the recovery stress in constrained samples of the above mentioned alloy that were heated to $160^{\circ} \mathrm{C}$ and held at that temperature for $20 \min$ [14]. After a careful measurement of the temperature distribution in the climate chamber during heating, it could be excluded that this effect is a result from temperature inhomogeneities. This led to the assumption that the stress increase is the result of a delayed transformation from the $\varepsilon$ to the $\gamma$ phase. If the $\varepsilon \rightarrow \gamma$ transformation is time-dependent, it can be suspected that the $\gamma \rightarrow \varepsilon$ transformation 
occurring during mechanical loading is also time dependent. As a consequence, it can be expected that the alloy exhibits creep when kept at a constant load, or a stress relaxation when the strain is kept constant. Considering the above mentioned application as prestressing element in concrete, creep or stress relaxation at low temperatures can have a negative impact on the performance of the concrete structure, and a thorough understanding of those phenomena is required.

In the present work, the low temperature creep and stress relaxation behavior of the Fe-based SMA Fe$17 \mathrm{Mn}-6 \mathrm{Si}-10 \mathrm{Cr}-4 \mathrm{Ni}-1(\mathrm{~V}, \mathrm{C})$ in the temperature range $-45^{\circ} \mathrm{C}<\mathrm{T}<50^{\circ} \mathrm{C}$ was systematically investigated in stress and strain controlled step-wise tensile tests as well as in stress-temperature tests with elongated and constrained tensile specimens. To the author`s best knowledge temperature dependent creep and stress relaxation are studied in detail for the first time for FeMnSi based shape memory alloys.

\section{Experiments and methods}

\subsection{Material and specimen preparation}

An Fe-based SMA alloy with the chemical composition $\mathrm{Fe}-17 \mathrm{Mn}-5 \mathrm{Si}-10 \mathrm{Cr}-4 \mathrm{Ni}-1(\mathrm{~V}, \mathrm{C})$ (ma.-\%) was used for the study. The manufacturing process, the thermo-mechanical treatment as well as the specimen preparation have been described previously [16]. The phase change temperatures for stressfree conditions as determined by differential scanning calorimetry (DSC) are $-64,-60,103$ and $162^{\circ} \mathrm{C}$ for $M f, M s, A s$, and $A f$, respectively [9].

The optical micrograph of the material etched with a solution of $\mathrm{H}_{2} \mathrm{O}_{2}(35 \%) / \mathrm{HNO} 3(65 \%) / \mathrm{HCl}$ (32\%) with the ratio 7/30/9 is shown in Figure 1 a). The individual grains as well as the precipitated carbides are clearly visible. Figure $1 \mathrm{~b}$ ) shows the SEM micrograph of the same sample with the carbides in the matrix as well as on the grain boundaries. 


\subsection{Experimental setup and test protocols}

Step-wise stress-strain tests at different constant temperatures between $-45^{\circ} \mathrm{C}$ and $50^{\circ} \mathrm{C}$ were performed using a Zwick/Roell Z020 tensile testing machine equipped with a climate chamber. Additional tests at room temperature were performed with a Kammrath \& Weiss miniaturized tensile testing machine which could be installed inside a scanning electron microscope for in-situ tensile tests.

The creep behavior in the above temperature range was characterized in stress-controlled tests. Stress was increased linearly with intermittent holding periods of 200, 300, 400, 500 and $600 \mathrm{MPa}$. While the stress was kept constant, the strain was monitored as a function of time over 30 minutes holding time. In general, a loading rate of $3.33 \mathrm{MPa} \mathrm{s}^{-1}$ was selected. To study the effect of the load increase rate on the creep strain, additional tests with a load increase rate of $1.11 \mathrm{MPa} \mathrm{s}^{-1}, 0.11 \mathrm{MPa} \mathrm{s}^{-1}$, and $0.033 \mathrm{MPa}$ $\mathrm{s}^{-1}$ were performed.

Phase maps after 30 min creep at $600 \mathrm{MPa}$ were acquired by Electron Back-Scatter Diffraction (EBSD) on a FEI XLF30-FEG Scanning Electron Microscope SEM equipped with an Oxford Instruments Aztec acquisition system, at low magnification (x150) with a step size of $1 \mu \mathrm{m}$ and an electron voltage of $20 \mathrm{kV}$. The maps have a size of $825 \times 620$ pixels. The cut-off mean angle deviation (MAD) was chosen at $1^{\circ}$ and the obtained indexation rate is higher than $96 \%$. The maps were treated with HKL Channel5 to quantify the phase contents.

Phase changes were studied with a Bruker D8 diffractometer using $\mathrm{Cu} \mathrm{K} \alpha$ radiation. The beam was parallelized by a Goebel mirror and the amount of $\mathrm{Cu} K \beta$ radiation was reduced by a $0.012 \mathrm{~mm}$ thick Ni filter.

The stress relaxation behavior at low temperatures was characterized in strain controlled tests with a constant strain rate of $3.3 \times 10^{-3} \mathrm{~mm} \mathrm{~s}^{-1}$. The loading was interrupted at $0.25,0.5,1,2$ and $4 \%$ strain and the change of the stress was recorded as a function of time over 30 minutes holding time.

The recovery stress was determined by firstly imposing a tensile pre-strain of $4 \%$ at ambient temperature $\left(22^{\circ} \mathrm{C}\right)$ followed by a complete unloading down to a small tensile value of $20 \mathrm{MPa}$. This small prestress avoids possible compressive stresses and thus possible buckling due to thermal expansion during the heating treatments at constant strain. Then, the sample was heated to a step temperature be- 
tween $40^{\circ} \mathrm{C}$ and $160^{\circ} \mathrm{C}$, and cooled back to ambient temperature, keeping the strain constant. Heating and cooling of the samples was performed with a rate of $2{ }^{\circ} \mathrm{C} \cdot \mathrm{min}^{-1}$. During the heating stage, the temperature was kept constant at $40,80,120$ and $160^{\circ} \mathrm{C}$ for 30 minutes and the recovery stress was recorded as a function of time.

The microstructural changes over time at a constant load were characterized using the above mentioned Kammrath \& Weiss tensile tester in a SEM (Hitachi S-3700N). The specimen was loaded with a rate of $3.33 \mathrm{MPa} \mathrm{s}^{-1}$. The loading was stopped at constant stresses of 500 and $600 \mathrm{MPa}$, respectively. Secondary electron (SE) images of selected grains were taken directly after reaching the desired stress level as well as after 10, 20 and 30 minutes of holding time and carefully compared with each other with regard to microstructural changes. The $\varepsilon$-martensite bands form a characteristic surface topography on the tensile specimen, leading to pronounced contrasts in the SE images. The time for taking one picture was set to $10 \mathrm{~s}$ and was selected to ensure a reasonable image quality.

\section{Results}

\subsection{Stress-controlled tensile tests - low temperature creep}

Figure 2 shows isothermal stress-strain curves of specimens tested at different temperatures between -45 and $50^{\circ} \mathrm{C}$. The tests were performed with a load rate of $3.33 \mathrm{MPa} \mathrm{s}^{-1}$ with intermittent holding periods of $30 \mathrm{~min}$ at 200, 300, 400, 500 and $600 \mathrm{MPa}$. With decreasing testing temperature, the slope of the non-linear stress-strain curve decreases and the strain at a given constant stress increases. This temperature dependence has been already reported in [16] and has been related to the $\gamma \rightarrow \varepsilon$ transformation which is more pronounced at lower temperatures. In addition, a pronounced strain increase can be observed at the different holding stresses, indicating low-temperature creep of the alloy. It is interesting to note that the overall creep strain after 30 minutes is increasing with increasing holding stress, but also increasing with decreasing test temperature.

The insert in Figure 2 shows the creep strain as a function of time for different stresses at a testing temperature of $0^{\circ} \mathrm{C}$. Similar curves were derived from the tests at other testing temperatures (not shown here). At lower stresses, in the range 0- $400 \mathrm{MPa}$, the creep strain reaches an almost constant 
level during the 30 minutes testing time, whereas at higher stresses, the creep strain is still increasing. All creep curves can be well fitted with a logarithmic equation

$$
\varepsilon(t)=A \cdot \log (B \cdot t+1)
$$

where A and B are material dependent creep parameters and $t$ is the creep time. It should be noted that fitting with a simple power law did not lead to satisfying results.

For a better comparison of the different results the creep strain that was reached after $1000 \mathrm{~s}$ creep time is plotted as a function of the applied stress (Figure 3 a) as well as of the testing temperature (Figure $3 \mathrm{~b}$ ). After $1000 \mathrm{~s}$, the creep rates are rather low and the values from different tests can be easily compared. At constant test temperatures, the $1000 \mathrm{~s}$ creep strain increases exponentially with increasing stress. Surprisingly, creep is more pronounced at lower temperatures. A linear decrease of the $1000 \mathrm{~s}$ creep strain with increasing temperature can be observed for all stresses applied.

Figure 4 shows the creep strain rates calculated form the fitted logarithmic relationship in Eq. 1 during the first $200 \mathrm{~s}$ at 400 and $500 \mathrm{MPa}$. Independently of the test temperature, the creep rate decreases significantly in the first two minutes of the creep tests. It can be further seen that the creep rate generally increases with decreasing test temperature.

EBSD phase maps and the measured phase fractions of samples after testing at $-45^{\circ} \mathrm{C}, 0^{\circ} \mathrm{C}$ and $50^{\circ} \mathrm{C}$ are shown in Figure 5. The phase structure with the fcc $\gamma$-matrix (red) and the hcp $\varepsilon$-martensite phase (yellow) is clearly visible. The $\varepsilon$-martensite is characterized by a very fine lamellar structure inside the fcc grains. When the temperature is decreased from $50^{\circ} \mathrm{C}$ to $-45^{\circ} \mathrm{C}$ the amount of hcp martensite increases from $9 \%$ to $18 \%$ while the amount of austenite fcc decreases from $90 \%$ to $81 \%$. A small amount of $0.4 \%$ bet $\alpha^{6}$-martensite is measured at $-45^{\circ} \mathrm{C}$ while for $0{ }^{\circ} \mathrm{C}$ and $50{ }^{\circ} \mathrm{C}$ the amount of $\alpha^{6}$ is negligible. The $\alpha^{6}$-martensite is observed at the intersections of differently oriented hcp variants. The EBSD measurements provide a lower value for the amount of hcp martensite. Due to the limited lateral resolution of the EBSD system, the nm-sized stripes of the hcp phase are not fully identified as hcp, although fine lamellae can be observed in the band contrast images of the $\gamma$-phase in the EBSD maps. These bands are the consequence of the distortion field generated by the $\gamma \rightarrow \varepsilon$ phase transformation. 
The increasing fraction of $\varepsilon$-martensite with decreasing temperatures is confirmed by XRD measurements, as shown in Figure 6. While the fcc $(200)_{\gamma}$ peak decreases with decreasing deformation temperatures the hcp peaks $(10 \overline{1} 0)_{\varepsilon}$ and $(10 \overline{1} 1)_{\varepsilon}$ increase. For the specimen tested at $-45{ }^{\circ} \mathrm{C}$ a small bct $(110)_{\alpha}$, shoulder is observed. The fcc (111) peak overlaps with the hcp (0002). The slight increase at that position for decreasing temperatures is attributed to a decrease of fcc (111) and an increase of the hcp (0002) peak.

To investigate the influence of the load rate of the tensile test on the creep behavior during the constant-stress step, further tests with $0.033,0.11$ and $1.11 \mathrm{MPa} \mathrm{s}^{-1}$ load increase rates were performed at room temperature $\left(22^{\circ} \mathrm{C}\right)$. Figure 7 shows exemplarily for 500 and $600 \mathrm{MPa}$ holding stress the development of the creep strain as a function of time over 30 minutes holding time. It can be seen that the creep strain significantly decreases if the load increase rate is decreased, showing that creep occurs already during the loading. Even at the lowest load rate, low temperature creep can be clearly detected.

\subsection{Strain controlled tensile tests - stress relaxation}

Low temperature creep results in a stress relaxation over time if the strain is kept constant. Since $\mathrm{Fe}$ SMAs are considered to be used as pre-stressing elements, the stress-relaxation behavior needs to be investigated.

Figure 8 shows exemplarily a stress-strain curve recorded during a strain-controlled tensile test at room temperature. The loading was stopped for $30 \mathrm{~min}$ at different total strains between 0.25 and $4 \%$ and the stress was monitored as a function of time. A clear decrease of the stress can be observed during the holding period. The development of the stress as a function of time can be mathematically described with a power law according to Eq. 2:

$$
\sigma(t)=-k \cdot t^{n}
$$

The same tests were performed at $-45^{\circ} \mathrm{C}$ and $50^{\circ} \mathrm{C}$ in order to characterize the influence of the testing temperature. Figure 9 a) shows the influence of applied strain on the stress relaxation over time at room temperature. The larger the strain, the more pronounced the stress relaxation. In Figure $9 \mathrm{~b}$ ) the 
influence of the testing temperature on the stress relaxation is presented. Surprisingly, the stress relaxation is more pronounced at lower temperatures. A maximum stress relaxation of up about $60 \mathrm{MPa}$ was measured at $-45^{\circ} \mathrm{C}$, corresponding to a decrease of approximately $10 \%$.

\subsection{Stress-temperature tests}

Figure 10 a) shows the development of the recovery stress as a function of the temperature during heating of a prestrained sample. From the diagram, a stress increase of approximately $1 \mathrm{MPa}{ }^{\circ} \mathrm{C}^{-1} \mathrm{can}$ be derived. Taking into account the heating rate of $2{ }^{\circ} \mathrm{C} \mathrm{min}^{-1}$, this corresponds to a loading rate of $0.033 \mathrm{MPa} \mathrm{s}^{-1}$. The increase of the recovery stress with increasing temperature is a result of the shape memory effect, i.e. the back-transformation of $\varepsilon$-martensite into $\gamma$-austenite, which compensates the thermal expansion of the specimen. The small peaks at the holding temperatures show that the recovery stress continues to increase during holding. Upon further heating, the recovery stress first decreases as a result of the thermal expansion and the thermal inertia of the specimen before the shape memory effect becomes predominant and the recovery stress increases again. Figure $10 \mathrm{~b}$ ) shows the measured stress increase at $40,80,120$ and $160^{\circ} \mathrm{C}$ as a function of the holding time. At 40 and $80^{\circ} \mathrm{C}$, a maximum increase of $8 \mathrm{MPa}$ after 30 min was observed. The stress increase at 120 and $160^{\circ} \mathrm{C}$ was more pronounced, reaching values between 12 and $14 \mathrm{MPa}$. A careful measurement of the specimen temperature revealed a slight increase of approximately $1-1.5^{\circ} \mathrm{C}$ during the first two minutes at the constant temperatures. With regard to the slope of the stress-temperature curve, this might explain a stress increase of only $1.5 \mathrm{MPa}$, i.e. $10-20 \%$, of the measured stresses. The recovery stress increase over time during isothermal holding is small compared with the stress relaxation, which may be related to the rather low loading rate.

\section{Discussion}

Creep deformation in metals at low temperatures $<0.3 \mathrm{~T}_{\mathrm{m}}$ and below the yield stress has been reported to occur in several pure metals like aluminum, copper, cobalt, gold and nickel [20-22] but also in structural alloys like stainless steel and mild steel [23-27], titanium alloys [28-30], or magnesium al- 
loys [31]. However, those results have not attracted significant attention since the time-dependent deformations are usually rather small $(<0.1 \%)$ and occur only over hours to days, and failures due to creep are unlikely. For the above mentioned materials, low-temperature creep has been related to pure dislocation creep, and the creep strain as a function of time could be described with a simple power law or the logarithmic law given in Eq. 1. Dislocation creep is dependent on the density of mobile dislocations as well as on the dislocation mobility. Both parameters are increasing with increasing temperatures, and consequently, the creep strain is increasing.

In comparison with the results reported for the above mentioned materials, the creep strain reached in the current SMA after only 30 min holding time is large (more than $0.5 \%$ at $600 \mathrm{MPa}$ ), and more surprisingly, the creep strain increases as the test temperature decreases in the range $-45^{\circ} \mathrm{C}<\mathrm{T}<50^{\circ} \mathrm{C}$.

Zhao et al. [32] reported on rather high creep strains $>1 \%$ in a low-Mn TRIP (Transformation Induced Plasticity) steel consisting of ferrite, perlite and retained austenite that was tested in step-wise tensile tests at room temperature. The authors explained this observation by the martensitic transformation from retained austenite as a result of local strain-induced temperature changes in the material. The FeMnSi-based shape memory alloys show a close similarity to FeMn-based TRIP steels which also exhibit a stress induced transformation from the fcc-austenite phase to the martensite phase. According to the works of Olson et al. $[33,34]$, the plastic flow in TRIP steels in a certain temperature range is controlled by the stress-induced martensitic transformation. The plastic strain, $\varepsilon_{\mathrm{pl}}$, is proportional to the volume fraction of martensite, $\mathrm{f}$ :

$$
\varepsilon_{p l}=k(T) \cdot f
$$

However, the TRIP effect is mainly due to the formation of bct- $\alpha$ '-martensite and is not reversible. Nevertheless, the formation of comparably large amounts of $\varepsilon$-martensite of up to 20 vol. $\%$ can also be observed in TRIP steels, depending on the Mn amount [35]. As it has been shown in previous works [16], the plastic deformation in FeMnSi-alloys up to $4 \%$ strain is a result of the $\gamma \rightarrow \varepsilon$ transformation with minor formation of $\alpha^{\prime}$-martensite, and Eq. (3) can therefore be applied as well. A rough estimation of the maximum strain related to the fcc to hcp transformation is given by the underlying shear of 0.35. The content of hep martensite after $30 \mathrm{~min}$ at $-45^{\circ} \mathrm{C}$ at $600 \mathrm{MPa}$ is $18 \%$. Thus the maximum 
strain that can be expected from the transformation is $\varepsilon=6.3 \%$ which is more than ten times the deformation measured during the mechanical tests. The fact that the measured strain is lower than $\varepsilon=6.3 \%$ can be explained by the fact that the value of $6.3 \%$ is a maximum value assuming that an hcp variant can always be formed to fully accommodate the deformation along the tensile axis. Since we consider a polycrystal the transformation related strains depend on the grain orientation and thus the martensite transformation of an individual grain will only partially accommodate the deformation. However the estimation shows that is reasonable to assume that creep is caused by a fcc to hcp transformation.

The transformation kinetics and thus the deformation kinetics of steels undergoing a stress-induced transformation are generally controlled by nucleation and growth of the martensite phase. In common TRIP steels exhibiting mainly the formation of bct- $\alpha$ ' martensite, the kinetics of the isothermal martensite transformation is assumed to be nucleation-controlled due to the very rapid growth of the $\alpha$ ' martensite plates by shear parallel to the martensite habit plane $[33,34]$.

According to the model proposed by Kajiwara [36,37], the formation mechanism of $\varepsilon$-martensite is different, and the kinetics of the martensite growth cannot be neglected. $\varepsilon$-martensite is formed by generating dislocation loops every two (111) layers in the fcc lattice. This happens at pre-existing stacking faults or at instantaneously forming stacking faults. Under an externally applied uniaxial stress, faulting occurs mainly along one of three possible displacement vectors, resulting in the so-called "monopartial stacking" and macroscopic deformation. The creation of dislocation loops with Shockley partial Burgers vector is possible since the fcc and the hcp phases have very similar chemical free energies. The application of an external stress will then lead to the generation of a dislocation loop two layers away from the existing stacking fault to produce a four layer hcp-phase, followed by consecutive creation of dislocation loops at every second layer. When the martensite plate has thickened to some extent, a new martensite plate at a certain distance to the first martensite plate will be formed to relax the shape strain of the initially formed martensite plate. With further thickening, another martensite plate is nucleated nearby, and so on, until the maximum martensite fraction at a given stress and test temperature has been reached. Considering the low temperatures and comparably low stresses, the velocity of the moving dislocations involved in this process can be assumed to be rather low (i.e. in the 
range of $10^{-8} \mathrm{~m} \mathrm{~s}^{-1}$ according to a recent study by in-situ transmission microscopy on a $9 \mathrm{Cr}$ steel by Yamada and Sakai [38]) with only slight variations in the considered temperature interval.

As mentioned above, the amount of macroscopic plastic strain is directly related to the martensite fraction. With regard to our previous work [16], the critical stress required for the $\gamma \rightarrow \varepsilon$ transformation in the investigated FeMnSi-based alloy is a linear increasing function of temperature from approximately $180 \mathrm{MPa}$ at $-50^{\circ} \mathrm{C}$ to $250 \mathrm{MPa}$ at $120^{\circ} \mathrm{C}$, giving a slope of $0.41 \mathrm{MPa} /{ }^{\circ} \mathrm{C}$. In other words, the volume fraction of $\varepsilon$-martensite that is thermodynamically stable at a given stress increases as temperature decreases. This impact of stress on the phase transformation temperature for first order martensite phase transformations is generally described by the Clausius-Clapeyron equation. The EBSD and XRD measurements on creep tested samples mentioned above confirmed an increase of the hcp phase fraction when the testing temperature is decreased from $50^{\circ} \mathrm{C}$ to $-45^{\circ} \mathrm{C}$. At the same time, the creep at $600 \mathrm{MPa}$ after $30 \mathrm{~min}$ increases from $0.3 \%$ at $50^{\circ} \mathrm{C}$ to $0.6 \%$ at $-45^{\circ} \mathrm{C}$. As shown by the EBSD measurements the amount of bct phase is below $0.4 \%$ for all temperatures and is negligible. Thus, the amount of hcp martensite clearly correlates with the amount of creep as expected from Eq. 3. In addition, the stacking fault energy decreases with decreasing temperature [39], resulting in a higher density of stacking faults in the austenite and thus more nucleation sites at lower temperatures. This means that more martensite plates start growing simultaneously, resulting in a faster transformation and thus higher creep rates.

Those factors influencing the nucleation and growth of the new martensite plates seem to determine the martensite transformation kinetics. This cannot only explain the observed time-dependent stressstrain behavior in FeMnSi-alloys, but also why larger strains are generally achieved at the same stresses when the test are performed at lower temperatures and why creep is faster and more pronounced at $-45^{\circ} \mathrm{C}$ than at $0^{\circ} \mathrm{C}$ or $+50^{\circ} \mathrm{C}$. The time-dependent deformation at low temperatures in FeMnSi-based shape memory alloys can thus be called a transformation induced creep (TRIC).

Figure 11 shows schematically a simplified model for the growing of the martensite plates in an arbitrary grain at different temperatures for different applied stresses. In the initial state before loading (Figure $11 \mathrm{a}$ ), the material at the lower temperature is assumed to contain more stacking faults than the one at higher temperature. Those stacking faults are the nucleation sites for $\varepsilon$-martensite plates that start growing once the temperature-dependent critical stress is exceeded (Figure 11b). Consequently, 
more martensite plates form at the low temperature. If the stress is further increased, new martensite plates form at a certain distance from the initial martensite plates to compensate the lattice distortion induced by the former ones, and the initial martensite plates continue growing (Figure 11c). The insert on the right hand side in Figure 11b) shows schematically the change of the size of one martensite plate over time, indicating its continuing growth.

In order to support the theory of the delayed martensite growth, a stress-controlled in-situ tensile test in the SEM was performed. As shown in the EBSD images in Figure 5, the $\varepsilon$-martensite is characterized by a very fine lamellar structure. The martensite plates lead to the formation of a surface relief on the polished specimens [36] and can thus be observed using the secondary electron detector of the SEM. The load was applied with a rate of $3.33 \mathrm{~N} \mathrm{~s}^{-1}$ and kept constant at two loading steps, i.e. 500 and $600 \mathrm{MPa}$, for 30 minutes. SEM micrographs of selected grains that showed pronounced features of martensite formation were taken immediately after reaching the loading step as well as after $30 \mathrm{mi}-$ nutes of holding at constant load. The initial microstructure of the unloaded sample including the direction of tensile load is shown in Figure 12 a) as an overview image while Figure 12 b) focuses on one grain. Comparing Figure 12 b) and c) when the sample is loaded with $500 \mathrm{MPa}$ and held on this loading step for 30 min reveals that martensite plates formed within the shown grain which are more or less equidistant to each other and oriented perpendicular to the loading direction. After the tensile stress is increased to the final loading step of $600 \mathrm{MPa}$ and held for $30 \mathrm{~min}$, Figure $12 \mathrm{~d}$ ) confirms that the amount of martensite plates within the magnified grain increased while the distance between each individual plate reduced. In order to investigate the microstructural mechanisms in the material accounting for the significant creep strain in the sample when subjected to a constant load, SEM images were taken immediately after reaching a load of $600 \mathrm{MPa}$ and after keeping the load level constant for 1800 s. After an amplification of the image contrast, a change of the surface relief could be observed in some regions. In Figure $12 \mathrm{f}$ ) and h), which are magnified regions from Figure $12 \mathrm{~d}$ ) taken after 30 min holding time, the dark lines indicated by an arrow have increased in length in comparison with the status with no holding time (cf. Figure 12 e) and g). These results indicate, at least qualitatively, that the martensite plates continue growing during holding. 
The intergranular stress distribution determines which grains will primarily transform from austenite to martensite. In order to analyse the intergranular stresses a Schmid factor map of fcc grains (Figure 13) was generated from an EBSD map. Figure 13 also shows the martensite hcp phase. In the case where the intergranular stresses are equal to the macrostress the grains with the highest Schmid factor will transform primarily from austenite to martensite. As shown in Figure 13 some dark grains which have a rather low Schmid factor of 0.32 partially transformed to martensite while other grains with higher Schmid factors did not transform to martensite. This shows that intergranular stresses are not homogenously distributed along the tensile direction. To determine which grains preferentially transform to martensite the resolved shear stress (RSS) acting on the fcc-to-hcp transformation shear system $[112]\{111\}$ has to be taken into account. In this case not only the Schmid factor plays a role but the combination of Schmid factor and elastic modulus for a specific grain orientation. As a result, different amounts of martensite can form in different grains depending on the grain orientation with regard to the loading direction. When martensite forms within a specific grain, stresses will be redistributed leading to a temporal and spatial complex transformation phenomena.

Considering the results from the stress-temperature tests, it can be concluded that the reverse transformation $\varepsilon \rightarrow \gamma$ is also time dependent. It is assumed that the reverse transformation is accomplished by the successive reversion of thin plates one after another through the reverse movement of Shockley partial dislocations residing at the tip of each plate [36], which is again time-dependent. The higher the temperature, the larger the amount of back transformed austenite [16] and thus the larger the recovery stress at the end of the holding period.

The stress relaxation observed in strain-controlled tests is a direct consequence of the creep. It must not be neglected when considering the application of restrained FeMnSi-based SMA elements for prestressing or mechanical joining. In those cases, the elongated SMA is restrained in the concrete or by the materials to be joined and heated to the desired maximum temperature (e.g. $160^{\circ} \mathrm{C}$ ) and cooled back to room temperature [15]. While the stress increase in the heating stage is due to the shape memory effect, the increase in the cooling stage is a result of thermal contraction. However, the recovery stress can again exceed the threshold for the formation of $\varepsilon$-martensite, which is indicated by a nonlinear shape of the stress-temperature curve during cooling [15]. Depending on the applied strain and 
the temperature, the relaxed stress can be more than $60 \mathrm{MPa}$. In particular at $0.5 \%$ strain, which corresponds to a stress of approximately $350 \mathrm{MPa}$ and which corresponds to a typical recovery stress value of a specimen deformed by $4 \%$ heated to $160^{\circ} \mathrm{C}$ and cooled down to room temperature [15], a stress relaxation of $35 \mathrm{MPa}$, i.e. $10 \%$ of the initial stress, was measured after 30 minutes. However, similar to the creep strain, it is expected that the relaxed stress depends on the loading rate (in tensile tests) or the heating/cooling rate (in stress-temperature tests). If the loading rate or the heating/cooling rates are small as it might be the case e.g. during prestressing of concrete [18], the transformations are mostly completed when the target strain or temperature are reached. The creep and relaxation, respectively, would then be less pronounced as can be seen in Figure 4. For practical applications, however, not the prestress directly developed after heating but a $10 \%$ lower value should be considered for safety reasons.

\section{Summary}

The low-temperature creep and stress relaxation behavior of the Fe-based SMA Fe-17Mn-6Si-10Cr$4 \mathrm{Ni}-1(\mathrm{~V}, \mathrm{C})$ was characterized in step-wise stress and strain controlled tensile tests in the temperature range $-45^{\circ} \mathrm{C}<\mathrm{T}<50^{\circ} \mathrm{C}$. The creep strains that were measured after 30 min holding time at constant stresses were about one order of magnitude higher than creep strains reported for other materials such as high strength steels or Ti alloys. Moreover, a stress decrease of up to $10 \%$ of the initial holding stress was observed. Both creep and stress relaxation become more pronounced, and the creep rate is increased, when the testing temperature is decreased. Those phenomena are explained by the formation of stress induced $\varepsilon$-martensite from the parent $\gamma$-austenite phase during mechanical loading. According to Kajiwara's model, $\varepsilon$-martensite plates are formed step by step at stacking faults by the generation of dislocation loops on every second layer of the fcc lattice. After a critical size is reached, new martensite plates form at a certain distance from the first plate to compensate the shape strain. These processes are time dependent. At low temperatures, more martensite becomes thermodynamically stable, and thus higher creep strains (or larger stress relaxation) are achieved. In addition, it is likely that the stacking fault density increases with decreasing temperatures, leading to more nucleation sites for the formation of $\varepsilon$-martensite plates and, as a consequence, to a higher creep rate. The time-dependent 
deformation at low temperatures in FeMnSi-based shape memory alloys can thus be considered as transformation induced creep (TRIC). Since Fe-based SMAs are considered e.g. for the prestressing of concrete structures or as coupling devices, knowledge on their time-dependent stress-strain behavior at low temperatures is important for security reasons.

\section{Acknowledgement}

The financial support by the Swiss National Science Foundation (SNSF grant No. 200021_150109 / 1) as well as by the company re-Fer AG, Wollerau, Switzerland, is gratefully acknowledged.

\section{References}

[1] A. Sato, E. Chisima, K. Soma, Acta Metall 30 (1982) 1177-1183.

[2] H.C. Lin, K.M. Lin, Scripta Mater. 34 (1996) 343-347.

[3] H.C. Lin, K.M. Lin, T.S. Chou, Scripta Mater. 35 (1996) 879-884.

[4] A. Sato, H. Kubo, T. Maruyama, Mater. Trans. 47(3) (2006) 571-579.

[5] S. Kajiwara, D. Liu, T. Kikuchi, N. Shinya, Scripta Mater. 44(12) (2001) 2809-2814.

[6] S. Farjami, K. Hiraga, H. Kubo, Mater. Trans. 45 (2004) 930-935.

[7] W. Zhang, Y.H. Wen, N. Li, W. Xie, S. Wang, Mater. Sci. Eng. A 459 (2007) 324-329.

[8] Y.H. Wen, L.R. Xiong, N. Li, W. Zhang, Mater. Sci. Eng. A 474 (2008) 60-63.

[9] Z. Dong, U.E. Klotz, C. Leinenbach, A. Bergamini, C. Czaderski, M. Motavalli, Adv. Eng. Mater. 11 (2009) 40-44.

[10] C. Leinenbach, H. Kramer, C. Bernhard, D. Eifler, Adv. Eng. Mater. 14 (2012) 62-67.

[11] L. Janke, C. Czaderski, M. Motavalli, J. Ruth, Mater. Struct. 38 (2005) 578-592.

[12] E. Choi, Y.S. Chung, J.H. Choi, H.T. Kim H. Lee, Smart Mater. Struct. 19 (2010) 035024.

[13] K.A. Maji, I. Negret, J. Eng. Mech. 124 (1998) 1121-1128.

[14] A. Cladera, B. Weber, C. Leinenbach, C. Czaderski, M. Shahverdi, M. Motavalli, Constr. Build. Mater. 63 (2014) 281-293

[15] W.J. Lee, B. Weber, C. Leinenbach, Constr. Build. Mater. 95 (2015) 600-610

[16] W.J. Lee, B. Weber, G. Feltrin, C. Czaderski, M. Motavalli, C. Leinenbach, Mater. Sci. Eng. A 581 (2013) 1-7.

[17] W.J. Lee, B. Weber, G. Feltrin, C. Czaderski, M. Motavalli, C. Leinenbach, Smart Mater. Struct. 22 (2013) 125037.

[18] C. Czaderski, M. Shahverdi, R. Brönnimann, C. Leinenbach, M. Motavalli, Constr. Build. Mater. 56 (2014) 94-105

[19] M. Koster, W.J. Lee, M. Schwarzenberger, C. Leinenbach, Mater. Sci. Eng. A 100 (2015) 29-39.

[20] P.R. Thornton, P.B. Hirsch, Phil. Mag., 8(3) (1958) 738-761

[21] O.H. Wyatt, Phys. Soc. Proc. B 66 (1953) 459

[22] H. Conrad, Acta Metall. 6 (1958) 339-350 
[23] A. Oehlert, A. Atrens, Acta Metall. Mater. 42(5) (1994) 1493-1508

[24] S.H. Wang, Y.G. Zhang, W.X. Chen, J. Mater. Sci 36 (2001) 1931-1938

[25] T.H. Alden, Acta Metall. 5 (1987) 2621-2626

[26] E. Krempl, J. Mech. Phys. Solids 27 (1979) 363-375

[27] D. Kujawski, V. Kallianpur, E. Krempl, J. Mech. Phys. Solids 28 (1980) 129-148

[28] B.C. Odegard, A.W. Thompson, Metall. Trans. 5 (1974) 1207-1213

[29] M.A. Imam, C.M. Gilmore, Metall. Trans. A 10 (1979) 419-425

[30] T. Neeraj, D.H. Hou, G.S. Daehn, M.J. Mills, Acta Mater. 48 (2000) 1225-1238

[31] W.K. Miller, Metall. Trans. A 22 (1991) 873-877

[32] L. Zhao, B. Mainfroy, M. Janssen, A. Bakker, J. Sietsma, Scripta Mater 55 (2006) 287-290

[33] G.B. Olson, M. Cohen, Metall. Trans A, 13 (1982) 1907-1914

[34] G.B. Olson, M. Azrin, Metall. Trans. A, 9 (1987) 713-721

[35] O. Grässel, L. Krüger, G. Frommeyer, L.W. Meyer, Int. J. Plast. 16 (2000) 1391-1409

[36] S. Kajiwara, Mater. Sci. Eng. A 273-275 (1999) 67-88

[37] N. Bergeon, S. Kajiwara, T. Kikuchi, Acta Mater. 48 (2000) 4053-4064

[38] S. Yamada, T. Sakai, Microscopy 63(6) (2014) 449-461

[39] L. Remy, A. Pineau, B. Thomas, Mater. Sci. Eng. 36 (1978) 47-63 


\section{Figure captions}

Figure 1: Microstructure of the FeMnSi-SMA in the initial state a) optical micrograph, b) scanning electron micrograph

Figure 2: Stress-strain curves for the stepwise tensile tests at $-45,0$ and $+50^{\circ} \mathrm{C}$; development of the creep strain as a function of time at different constant stress levels at $\mathrm{T}=0^{\circ} \mathrm{C}$ (insert).

Figure 3: Creep strain after $1000 \mathrm{~s}$ holding time at different constant stresses and test temperatures; a) as a function of applied constant stress; $b$ ) as a function of test temperature.

Figure 4: Comparison of creep rates at constant loads of 500 and $400 \mathrm{MPa}$ for different testing temperatures.

Figure 5: Phase maps measured by EBSD of austenite fcc (red), martensite hcp (yellow) and martensite $\alpha^{\prime}$ (blue) measured after 30 min creep at temperatures of a) $-45^{\circ} \mathrm{C}$, b) $0{ }^{\circ} \mathrm{C}$ and c) $50{ }^{\circ} \mathrm{C}$. d) Evolution of phase fractions after $30 \mathrm{~min}$ creep at temperatures of $-45^{\circ} \mathrm{C}, 0{ }^{\circ} \mathrm{C}$ and $50{ }^{\circ} \mathrm{C}$.

Figure 6: XRD spectra of creep tested samples at different temperatures.

Figure 7: Development of creep strain as a function of time at 500 and $600 \mathrm{MPa}$ holding stress after loading with different load increase rates.

Figure 8: Stress-strain curve recorded during a strain-controlled tensile test at room temperature.

Figure 9: Isothermal stress relaxation as a function of holding time, a) for different constant strains at room temperature, $\mathrm{b}$ ) for a constant strain of $2 \%$ at different temperatures.

Figure 10: a) Stress-temperature curve of a sample pre-strained to $4 \%$, unloaded to $20 \mathrm{MPa}$ and subsequently heated to $160^{\circ} \mathrm{C}$ with isothermal holding steps at $40,80,120$ and $160^{\circ} \mathrm{C}$, respectively; b) relative stress increase as a function of holding time at the different temperatures.

Figure 11: Schematics of the martensite formation in an arbitrary grain during loading at different temperatures; a) initial stacking faults, b) growing of martensite plates from initial stacking faults and nucleation of new plates, c) growing and thickening of martensite plates.

Figure 12: SEM micrograph of unloaded microstructure in a) and b), at $500 \mathrm{MPa}$ after $30 \mathrm{~min}$ in c), at $600 \mathrm{MPa}$ after $30 \mathrm{~min}$ in d), high-contrast images of selected spots at $600 \mathrm{MPa}$ without holding time in e) and $\mathrm{g}$ ), with constant load for $30 \mathrm{~min}$ in $\mathrm{f}$ ) and $\mathrm{h}$ ); the arrows indicate features that have apparently changed after 30 minutes.

Figure 13: Schmid factor map calculated for the fcc grains from the EBSD map of a specimen deformed at $-45^{\circ} \mathrm{C}$ in the range $0.33-0.5$ in grey scale (dark = low SF and light $=$ high $\mathrm{SF}$ ). The tensile axis is vertical. The legend and the Schmid factor distribution is given in right upper side. The hcp martensitic plates are colored according their Euler angles. 


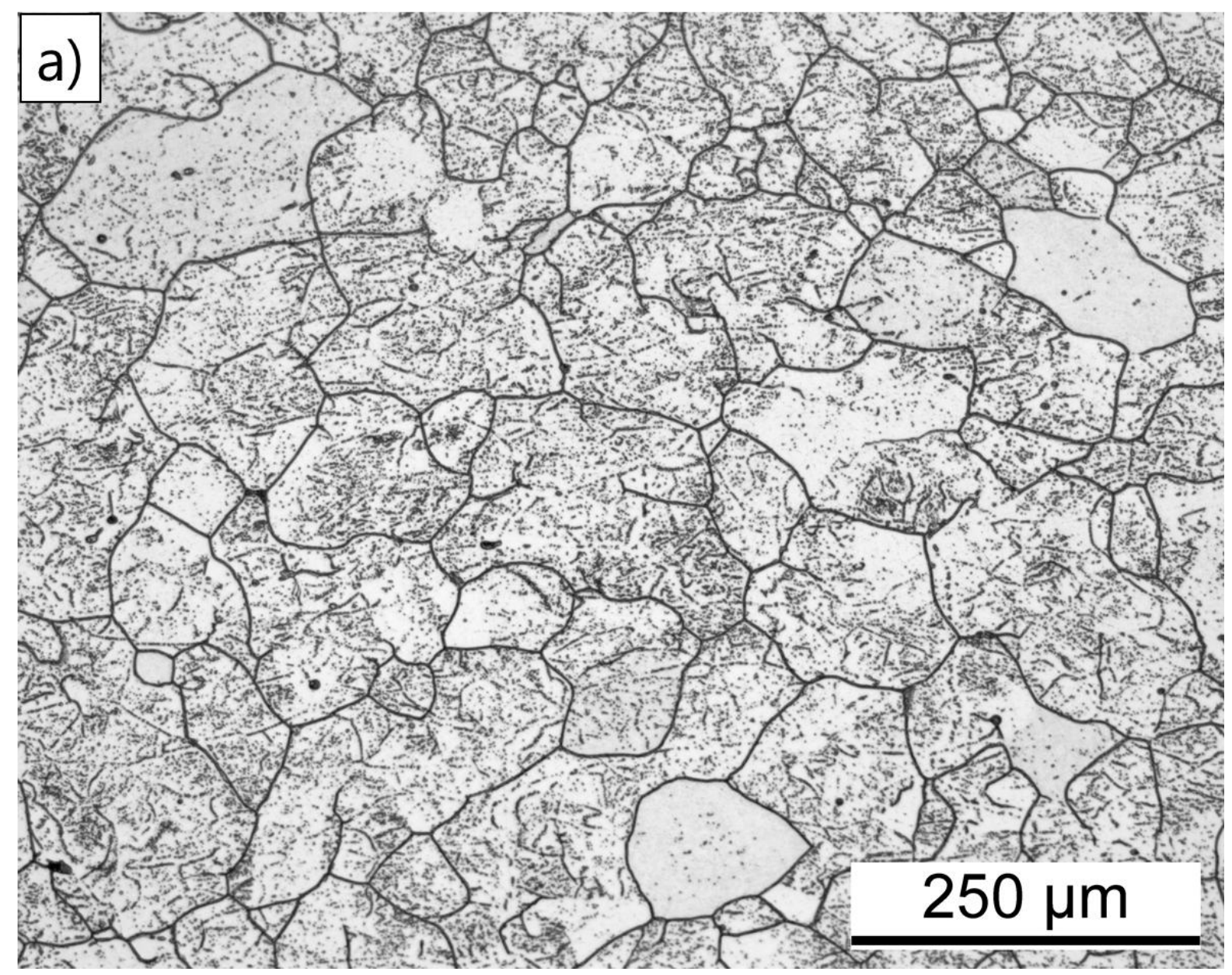




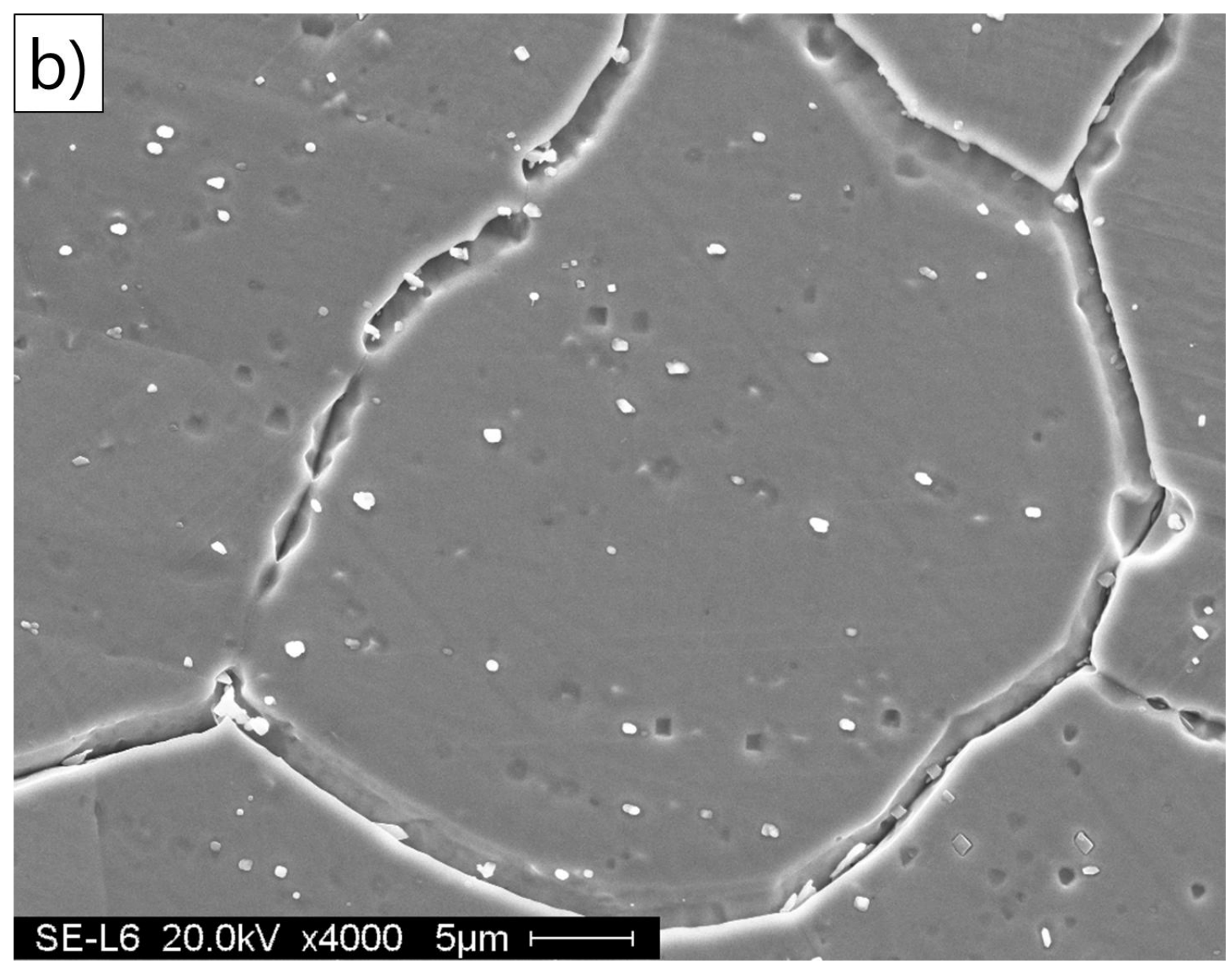




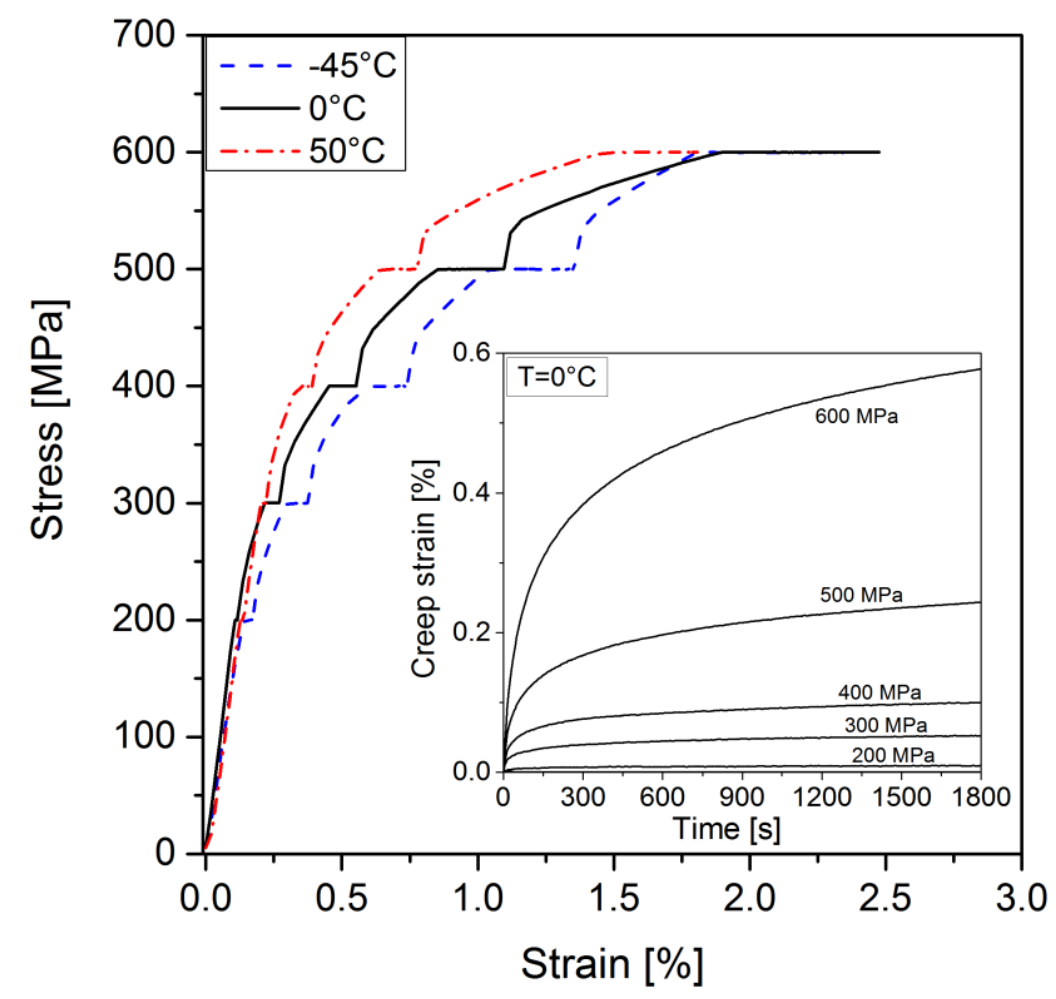




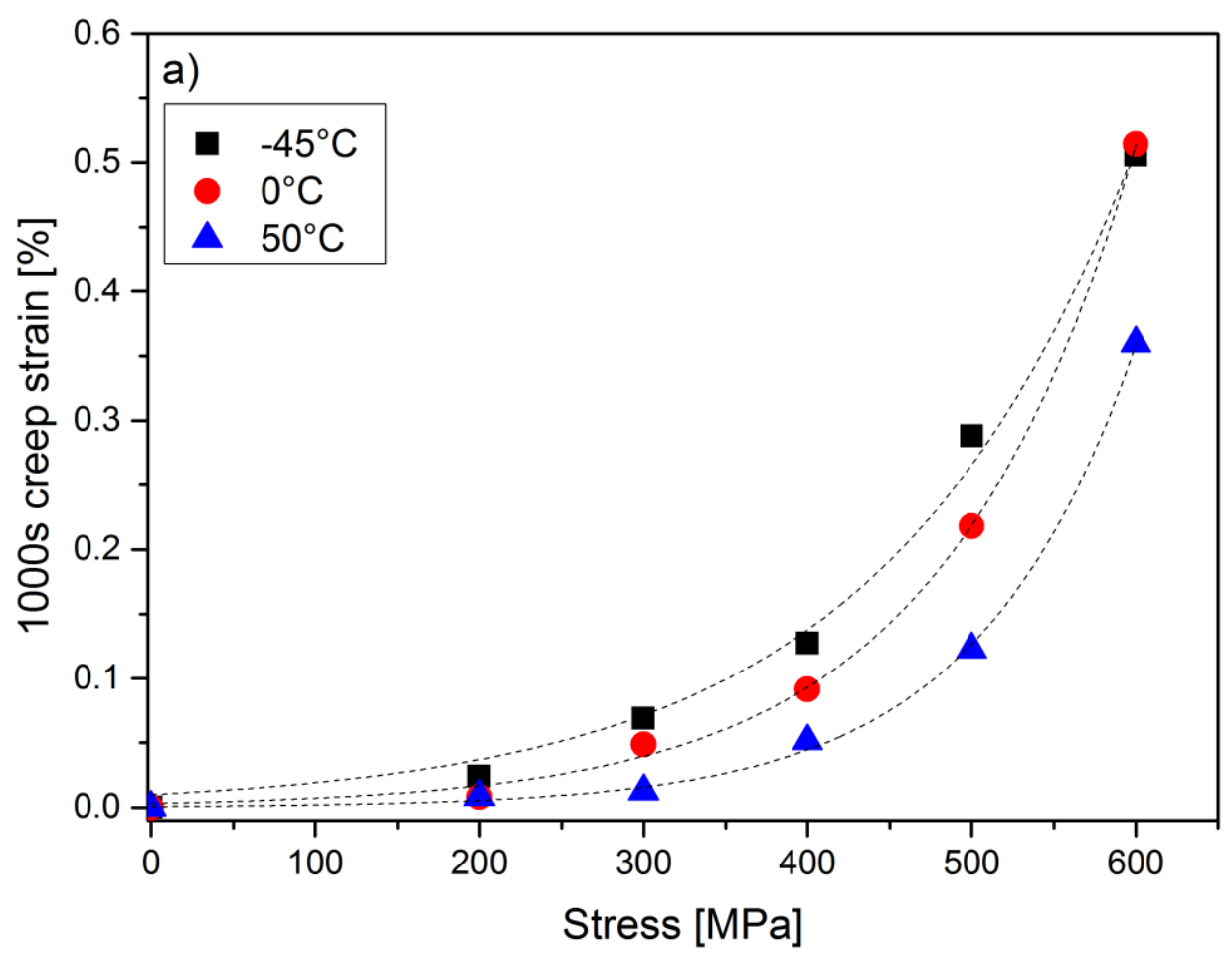




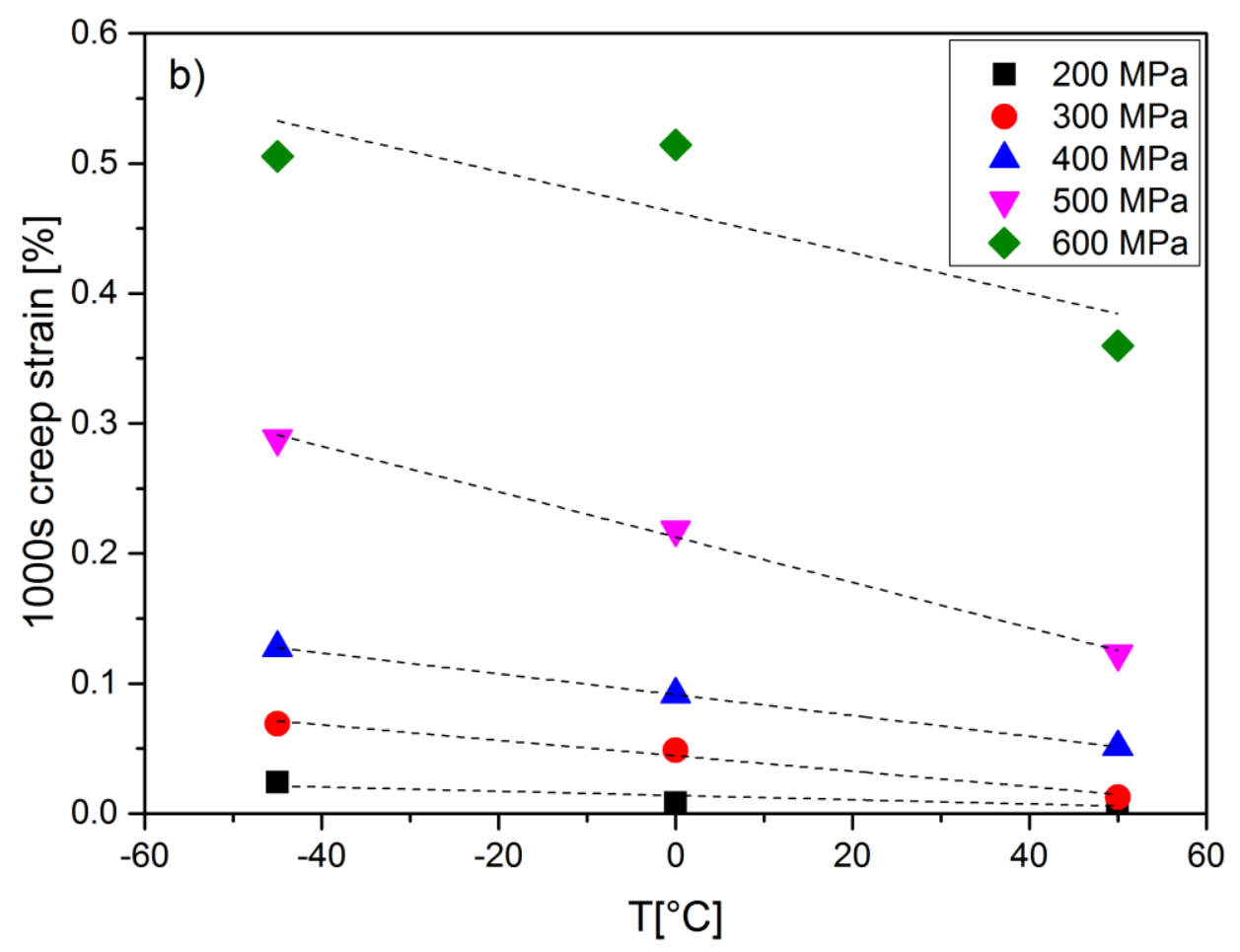




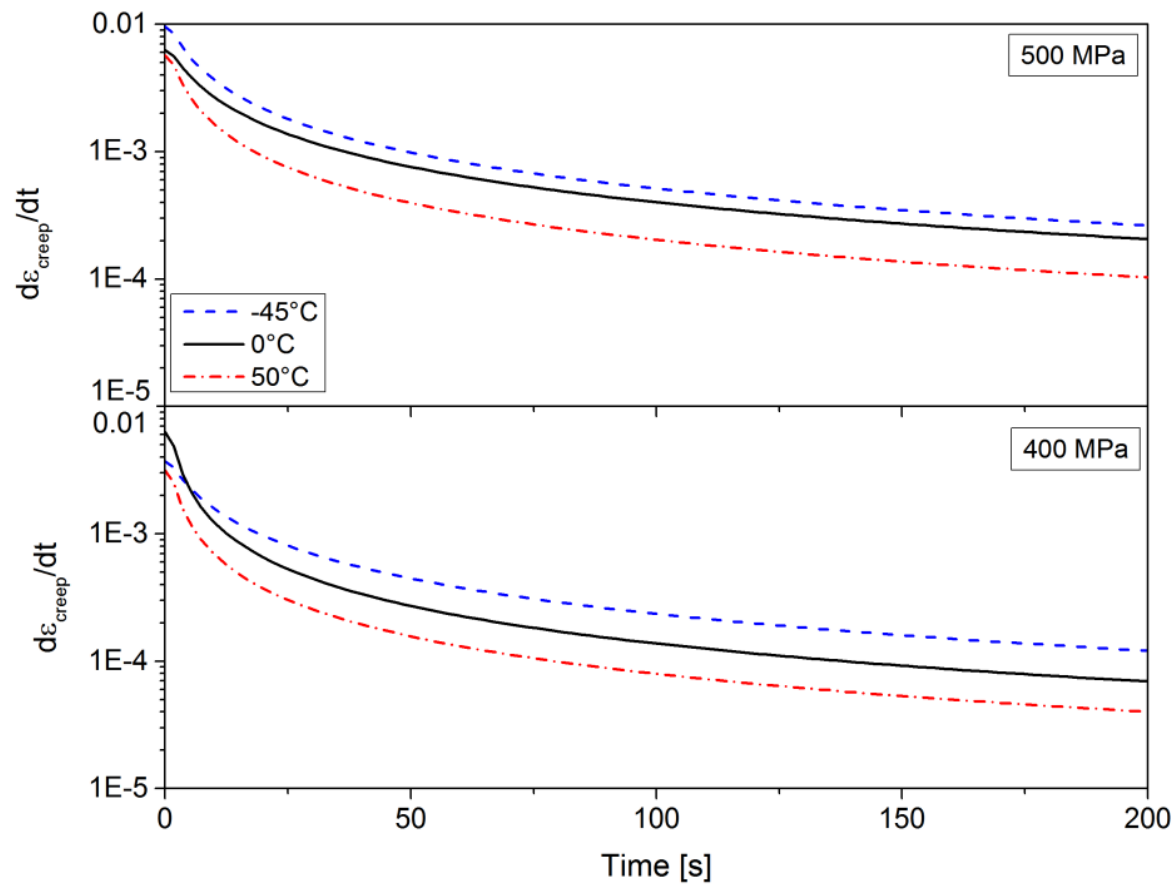




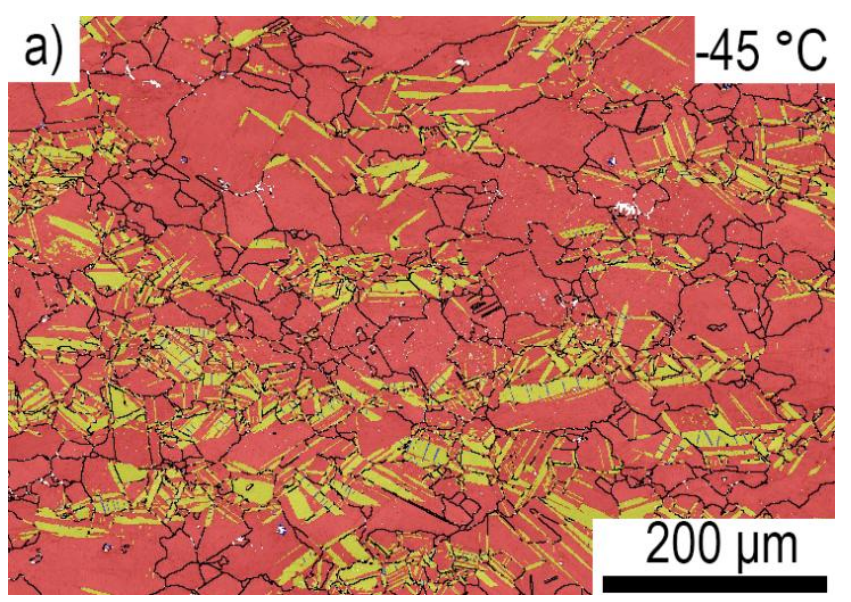




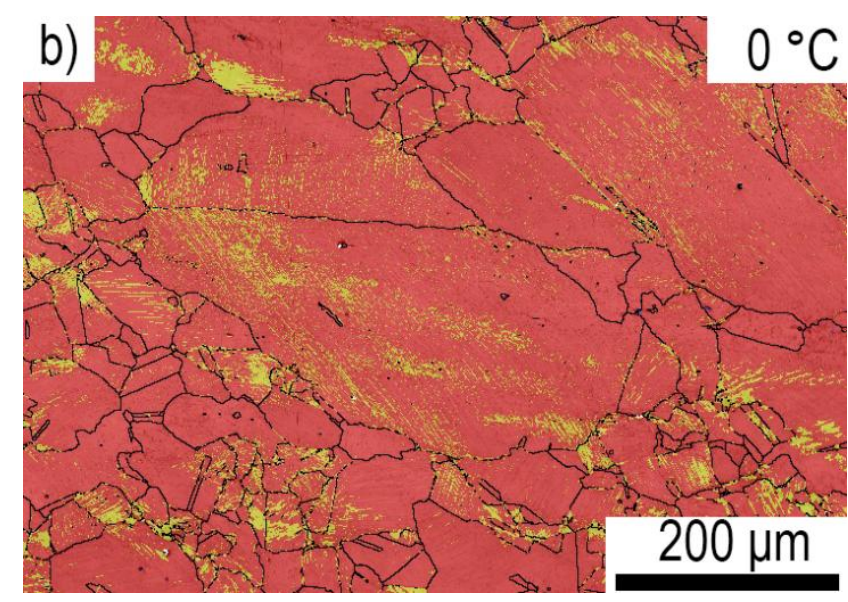




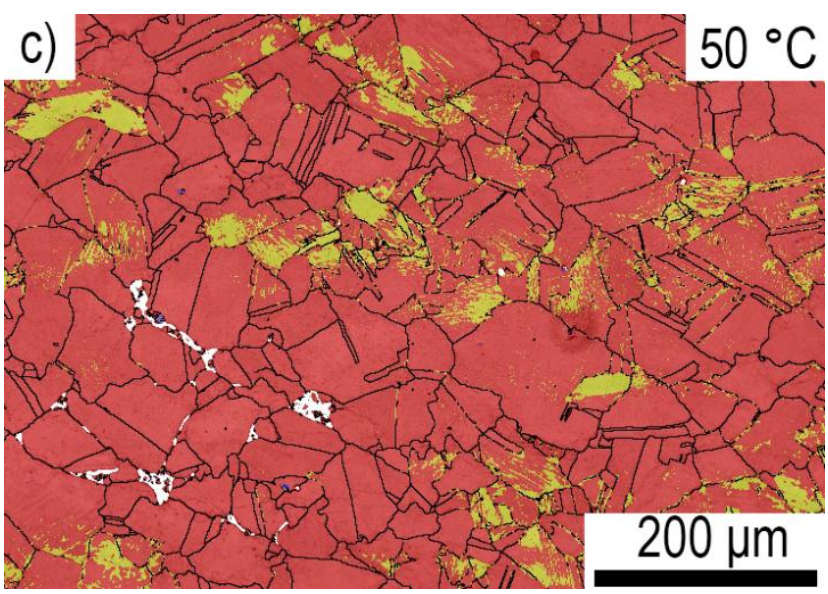


d)

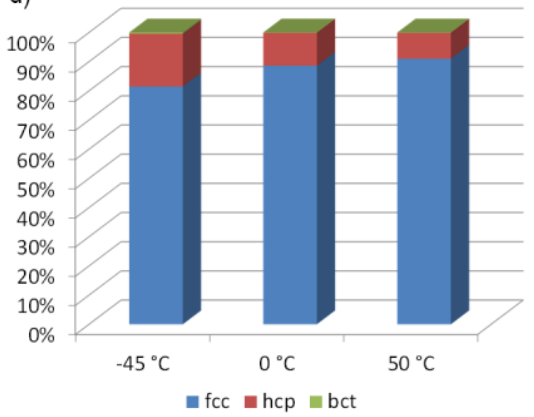




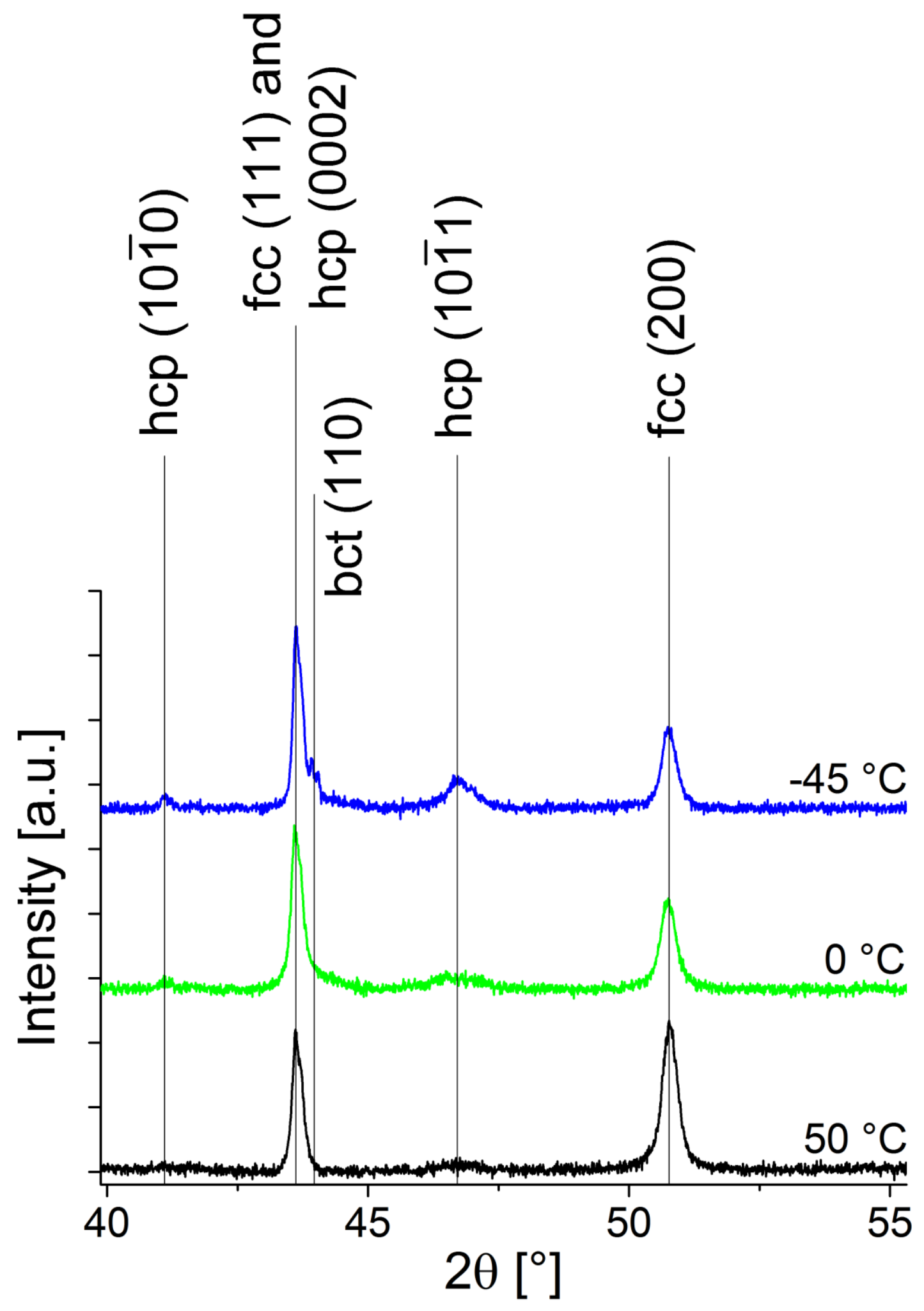




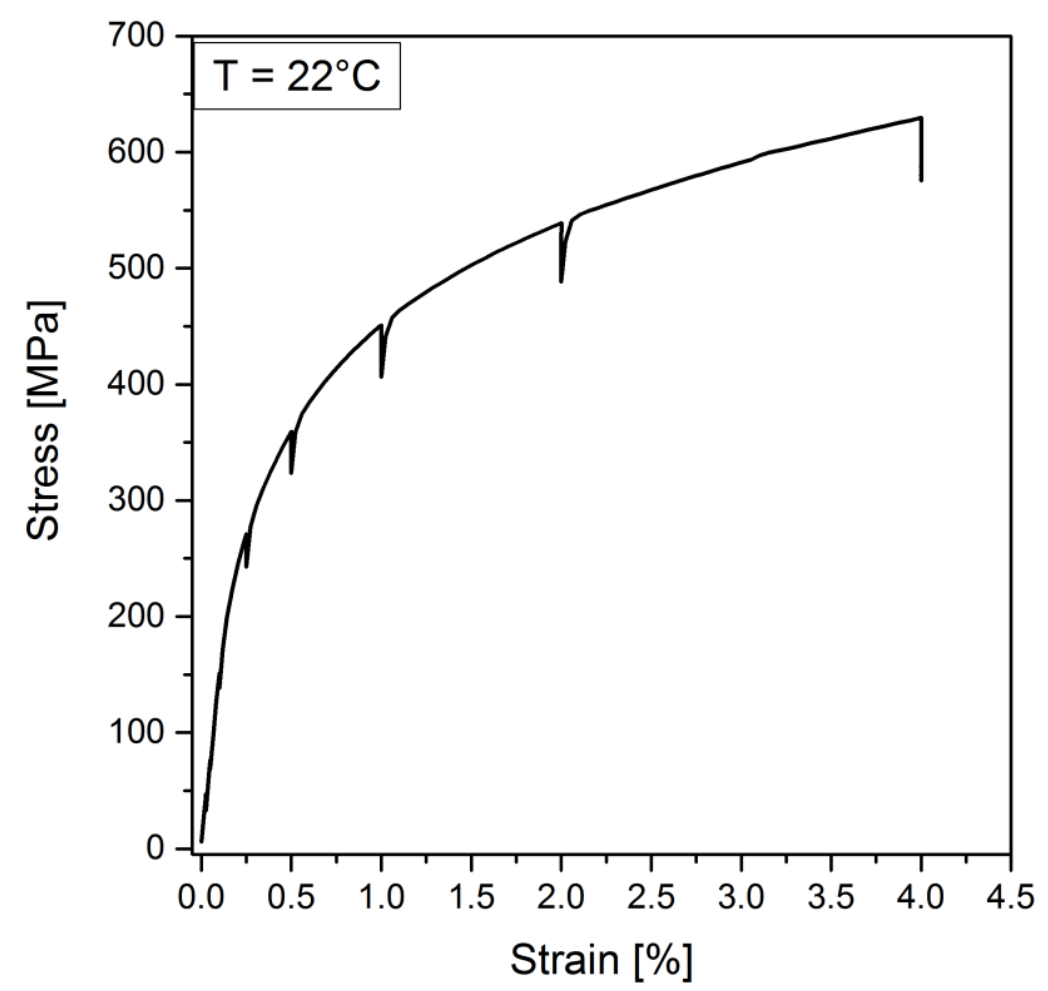




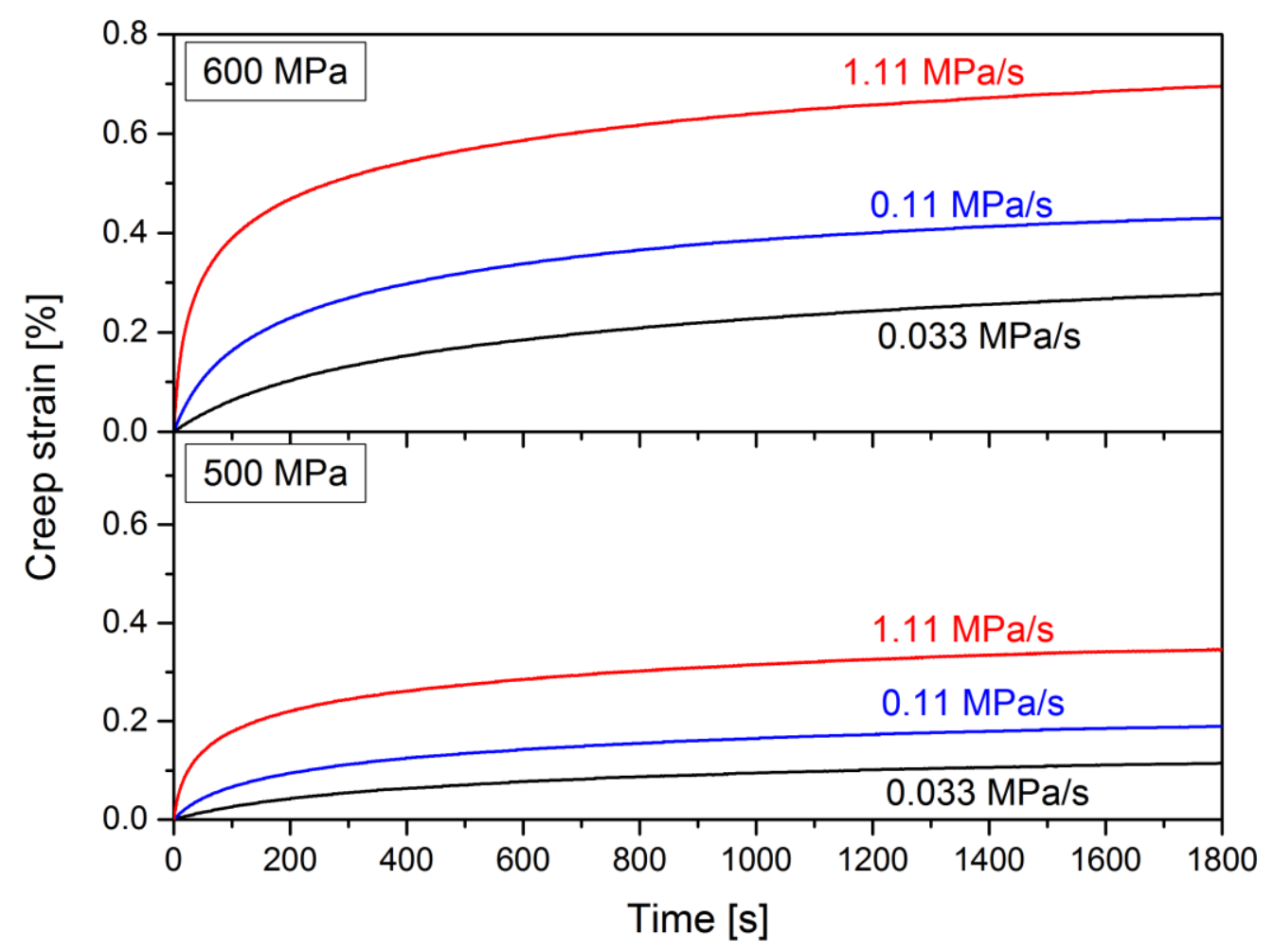




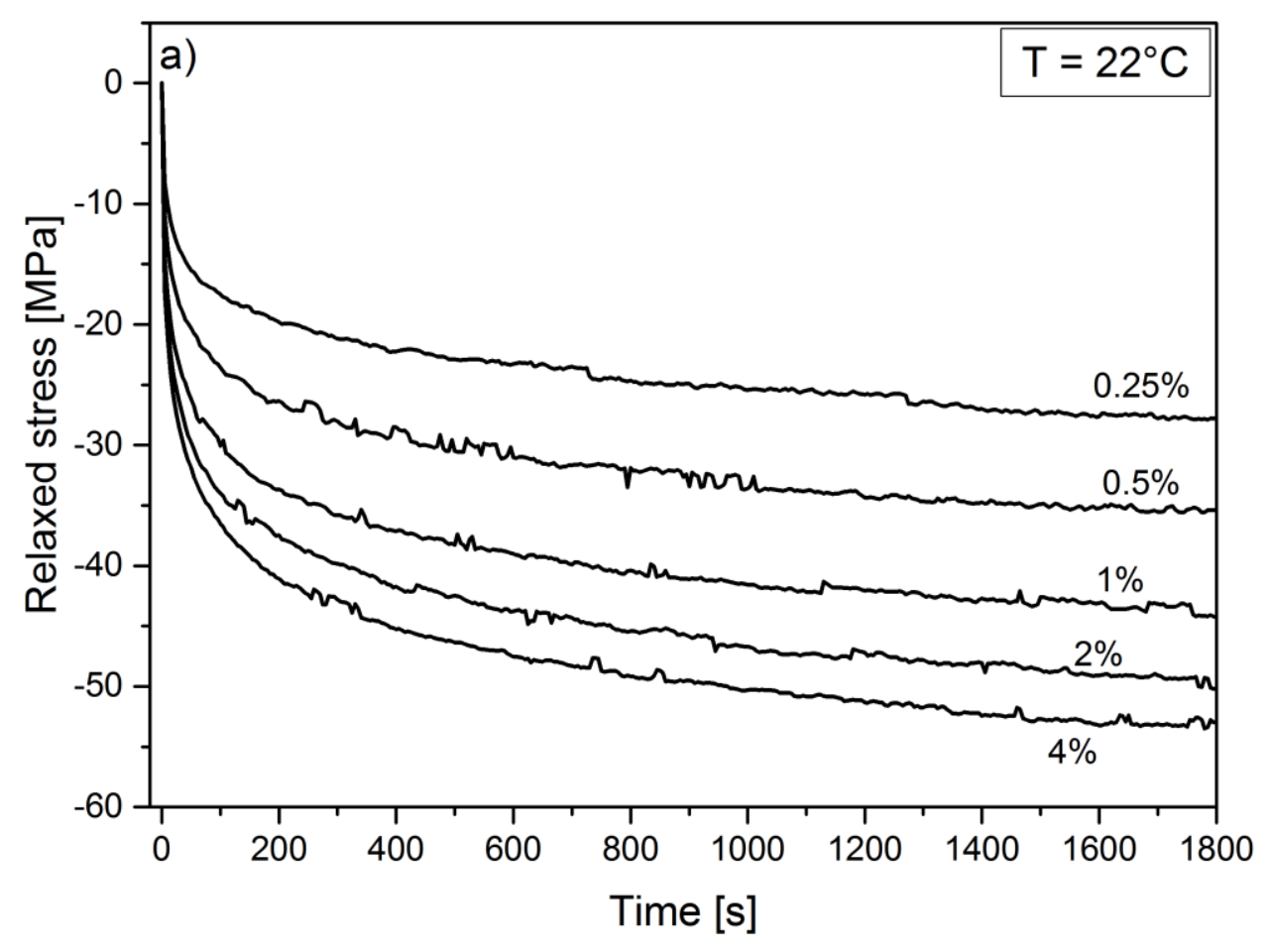




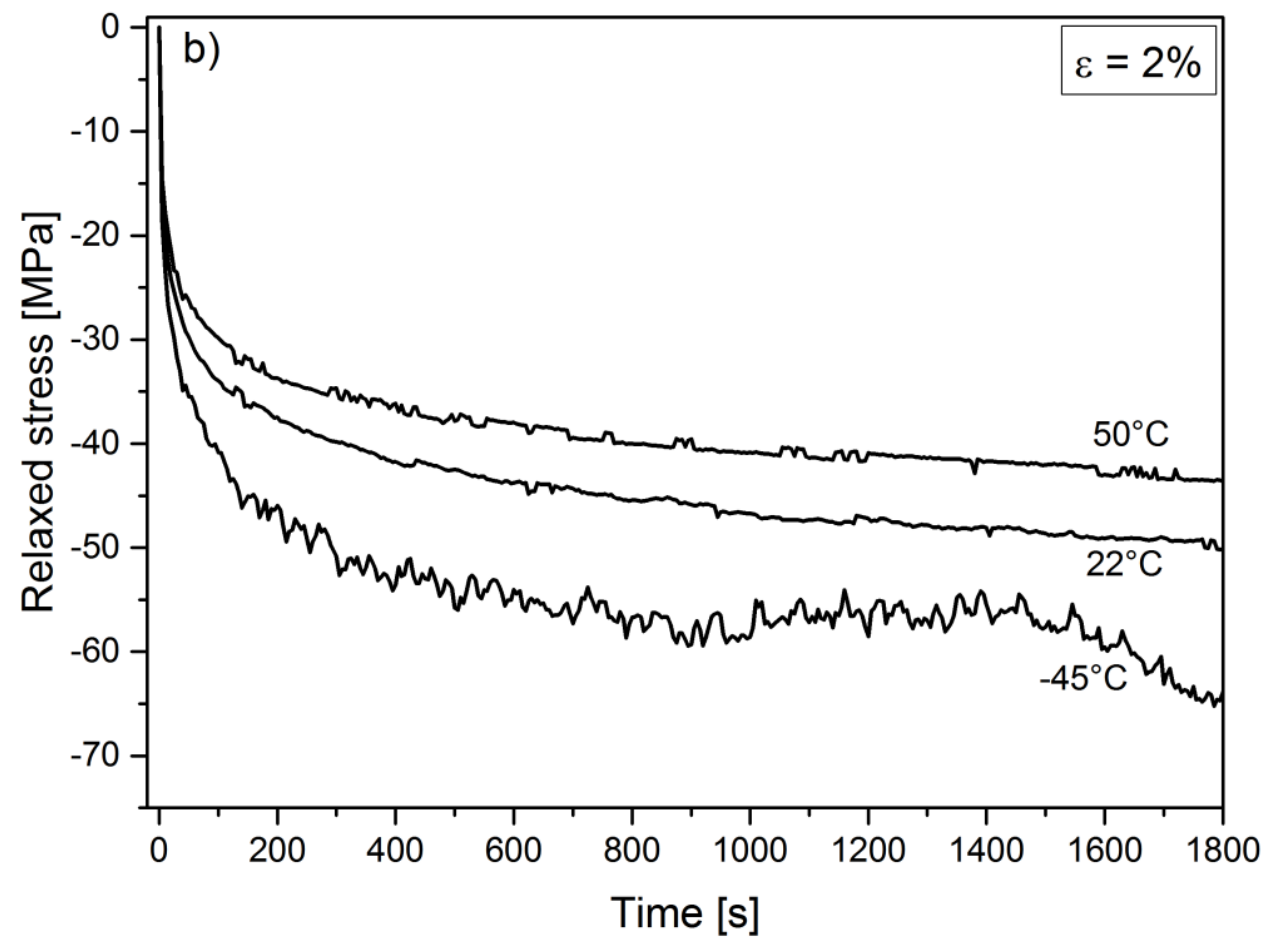




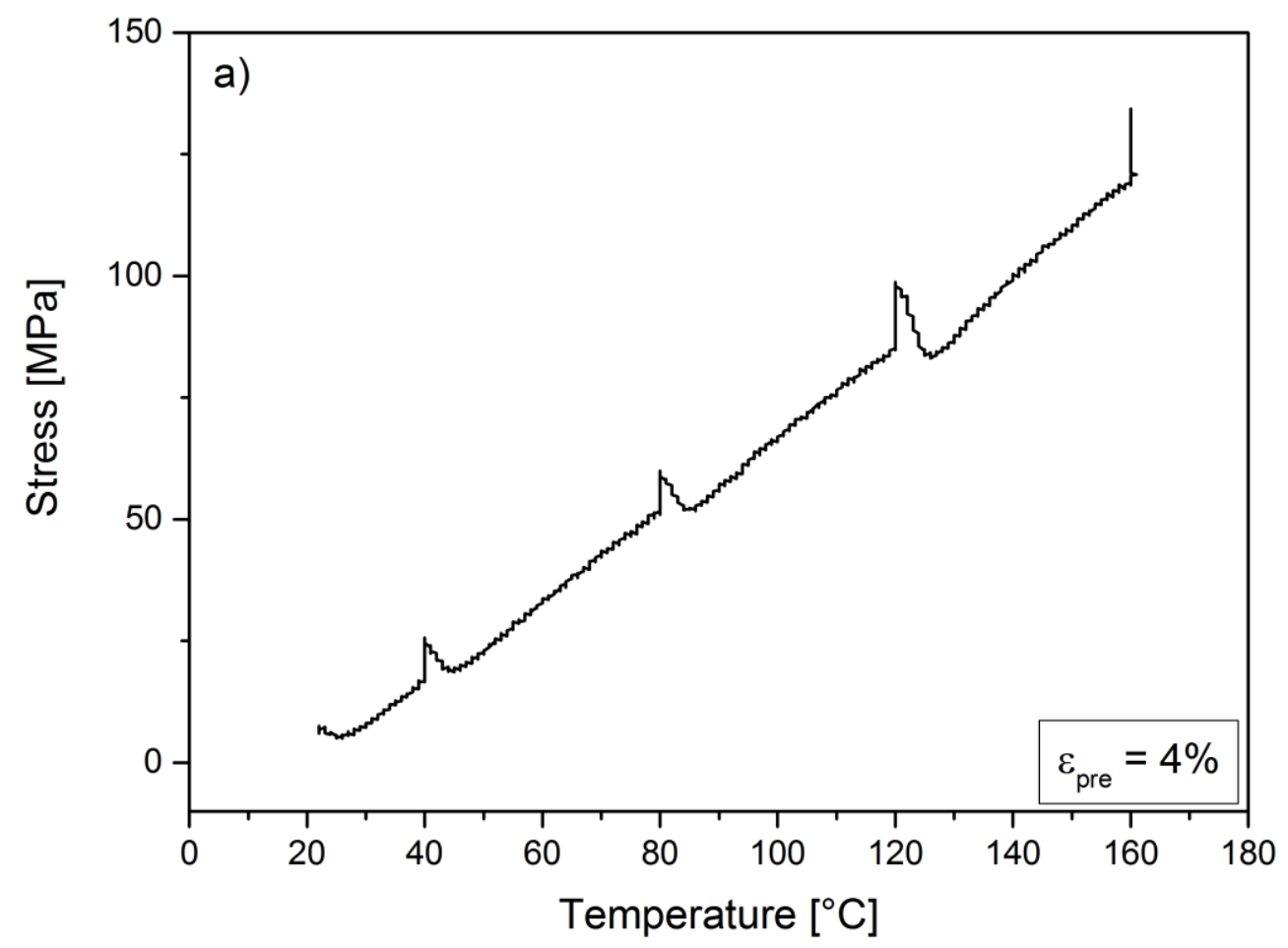




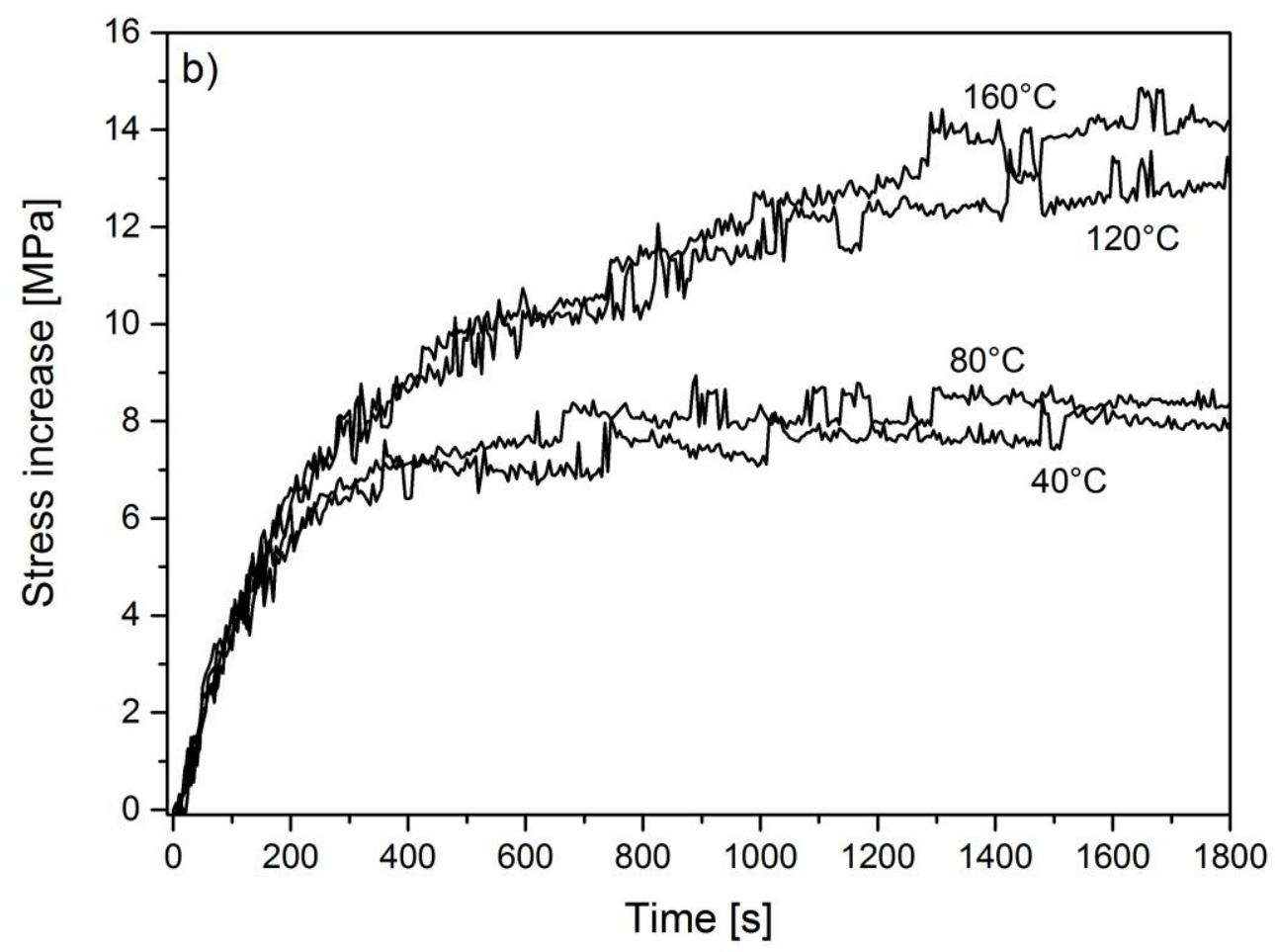




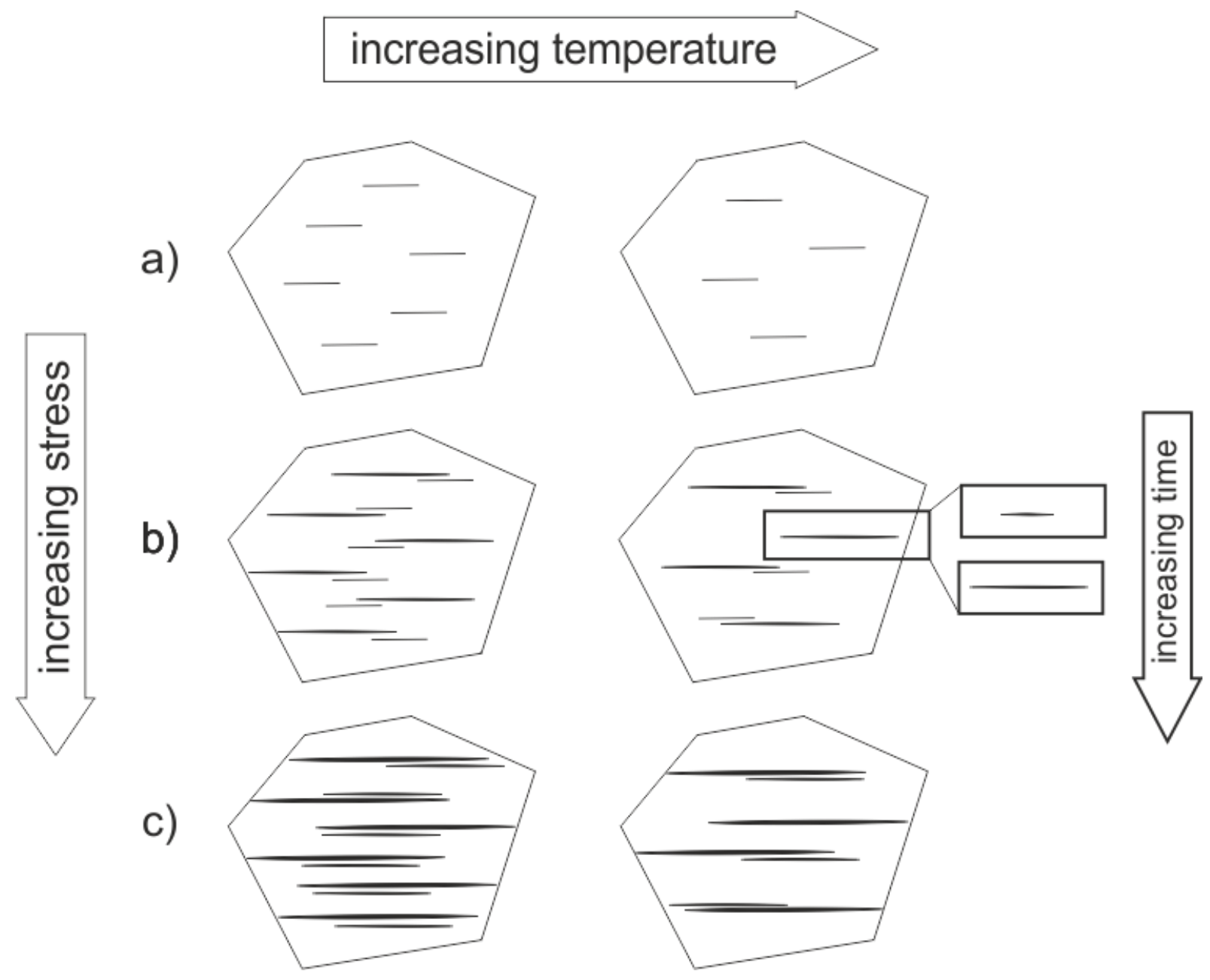




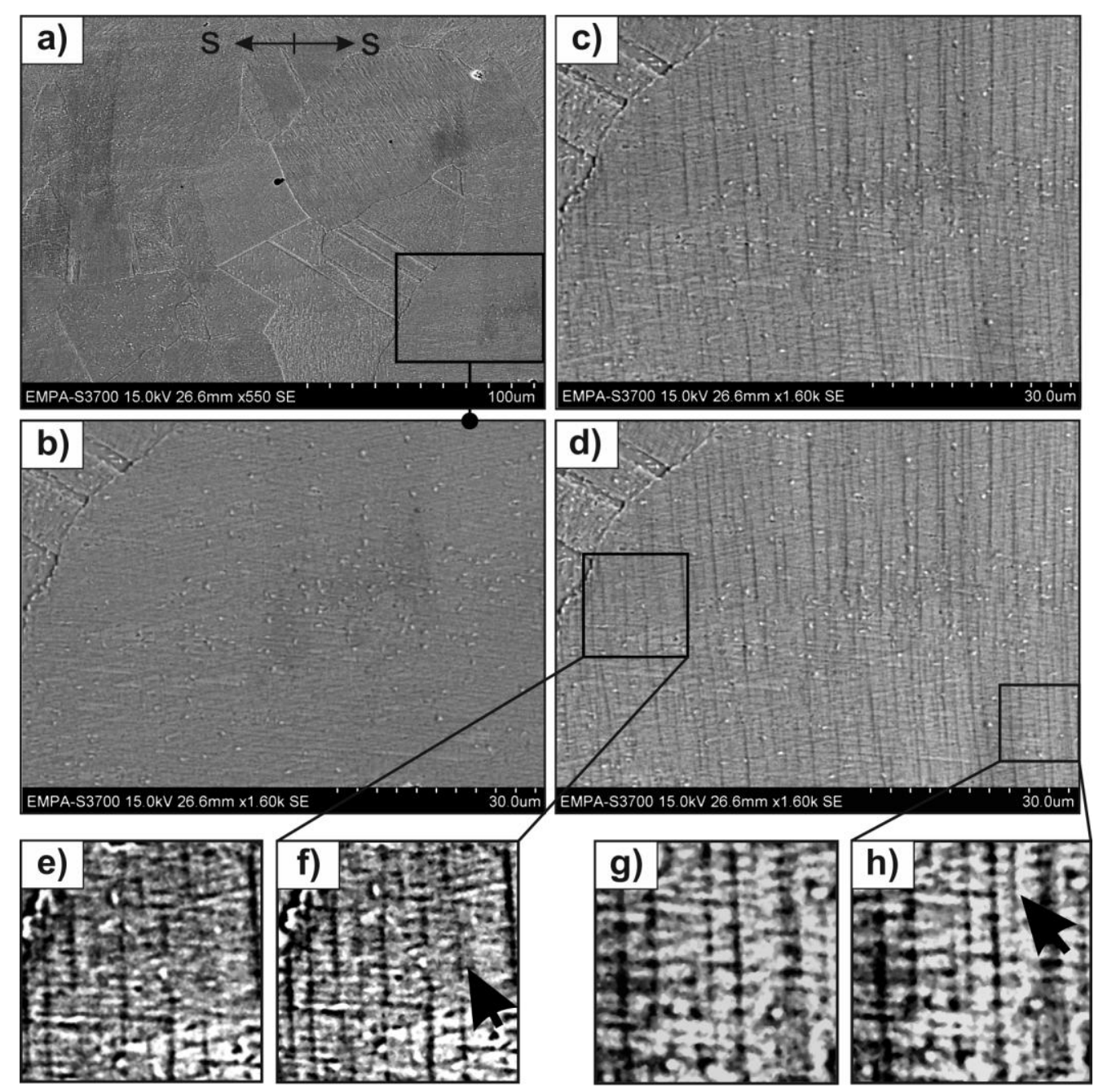




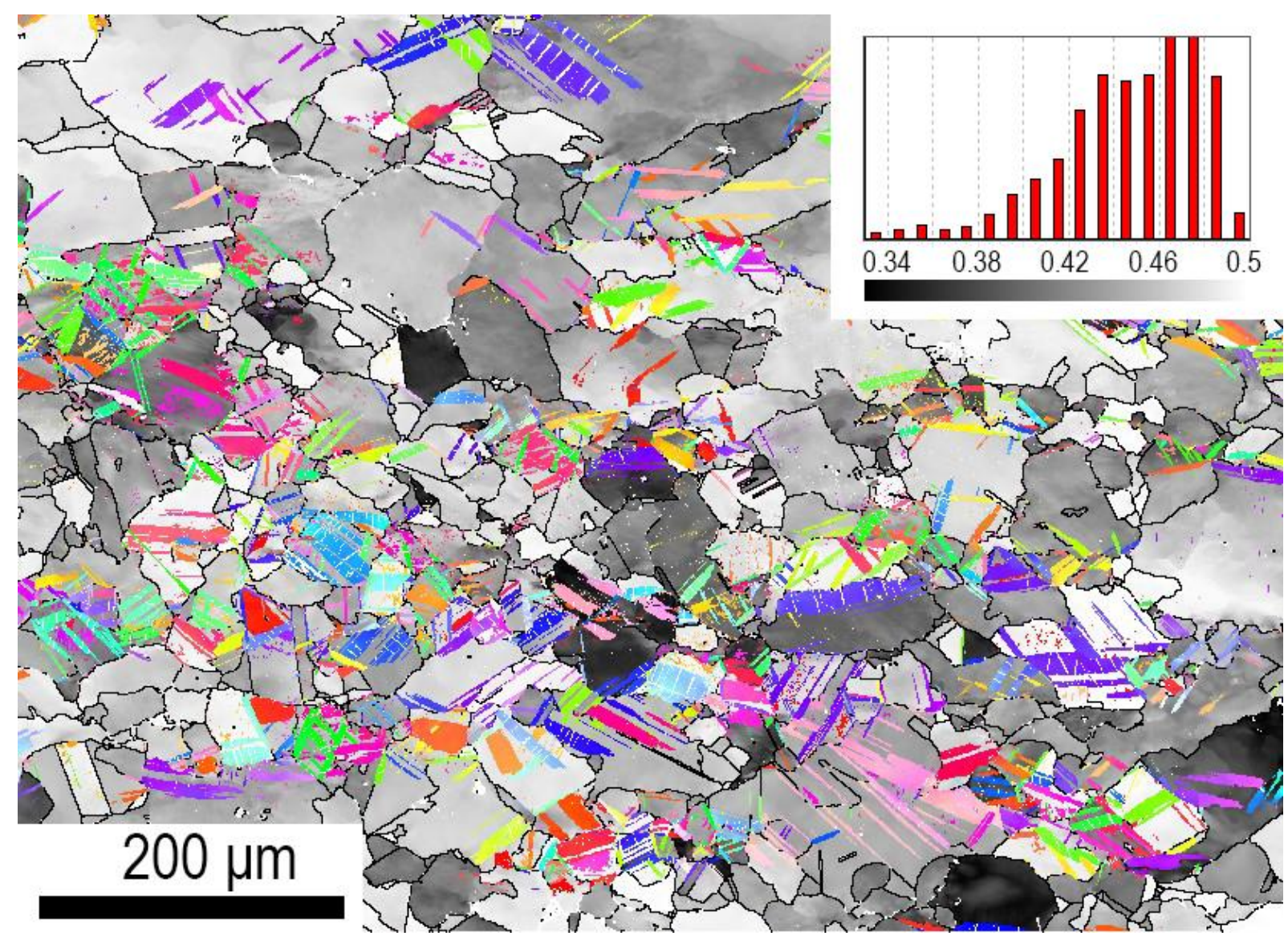

